\title{
ESTUDO DA SUBSTITUIÇÃO PARCIAL DO ADSORVENTE COMERCIAL POR CINZAS DE CAVACO DE MADEIRA NO BRANQUEAMENTO DO ÓLEO DE SOJA
}

\author{
A. C. P. ORO ${ }^{1}$, N. C. PEREIRA ${ }^{1}$ e O. C. da MOTTA LIMA ${ }^{1}$ \\ ${ }^{1}$ Universidade Estadual de Maringá, Departamento de Engenharia Química \\ E-mail para contato: andreiaoro@yahoo.com.br
}

\begin{abstract}
RESUMO - A biomassa representa uma fonte significativa de energia na matriz energética brasileira, sua crescente utilização para queima em cogerações de energia tem aumentado a geração do resíduo deste processamento, a cinza de caldeira, que necessita de disposição adequada. As cinzas provenientes da queima de biomassa têm potencial adsorvente a ser estudado, visto que, em sua maioria, são ricas em sílica e alumina. A etapa de branqueamento é uma etapa muito importante do processo de refino do industrial do óleo de soja. Atualmente, adsorventes do tipo argilas ativadas (terras ativadas) são os mais utilizados nesta etapa do processo para remoção principalmente de cor, clorofila e sabões dos óleos vegetais. Entretanto, a argila ativa representa grande impacto no custo do refino do óleo. O objetivo do trabalho foi caracterizar a cinza de cavaco de madeira in natura e analisar seu potencial como adsorvente de clorofila, cor vermelho, sabões e ácidos graxos livres do óleo de soja neutro-seco, comparando com o potencial de adsorção da terra ativada comercial. Os estudos mostraram que a substituição parcial é viável, uma vez que os potenciais de remoção encontrados para a cinza foram de $18 \%$ para clorofila, $28 \%$ para cor vermelho e $69 \%$ para sabões, não sendo efetiva para acidez.
\end{abstract}

\section{INTRODUÇÃO}

O refino do óleo de soja consiste de diversas etapas industriais que têm como objetivo a remoção de substâncias indesejáveis presentes no óleo de soja, tais como odor, gosto, fosfatídeos, gomas, entre outros. Ao final da etapa de refino, o óleo de soja refinado deve atender aos requisitos de qualidade dispostos na Instrução Normativa $n^{\circ}$ 49, de 22 de dezembro de 2006, do Ministério da Agricultura, Pecuária e Abastecimento (BRASIL, 2006) para então poder ser comercializado. As etapas que o óleo percorre ao longo do processo do refino são a degomagem, neutralização, branqueamento e desodorização.

Uma etapa muito importante dentro do processo de refino é o branqueamento, responsável pela eliminação de pigmentos naturais (como a clorofila e os carotenoides), o qual é realizado através da adsorção destas substâncias por um adsorvente específico, normalmente as argilas ativadas, carvão ativado e produtos à base de sílica. Estes, porém, impactam diretamente e de forma significativa o custo do refino do óleo. 


\section{9 a 22 de outubro de 2014 \\ Florianópolis/SC}

A utilização da biomassa como fonte de energia elétrica tem sido crescente no Brasil, principalmente em sistemas de cogeração. Nos últimos anos, a biomassa alcançou a segunda posição na matriz de fontes internas para geração de energia, sendo superada apenas pela fonte hídrica (ANEEL, 2008). As fontes mais comuns de biomassa para queima em caldeiras são o bagaço de cana de açúcar, cascas de arroz, cascas de côco e resíduos da indústria madeireira e de papel e celulose.

O processamento desta biomassa como combustível em usinas de cogeração gera elevados montantes de cinzas, resíduo sólido proveniente da queima da biomassa para geração de energia. As formas de disposição mais comuns deste resíduo são a sua aplicação em solo como condicionador e fonte de nutrientes e lançamento em aterros sanitários. Na literatura encontram-se pesquisas para utilização das cinzas da queima de biomassa como aditivo em argamassas de uso não estrutural, fíler em mantas asfálticas, matéria prima na produção de zeólitas para remoção de corantes em água, material adsorvente de corantes como o azul de metileno e diversas aplicações para remoção de substâncias indesejáveis de óleos vegetais.

Lin \& Lin (2009) estudaram o potencial adsorvente da cinza proveniente da queima de casca de amendoim no branqueamento de óleo de soja degomado com água e refinado via álcali e obtiveram resultados satisfatórios, apresentando a cinza como um adsorvente efetivo na remoção de peróxidos, fosfolipídeos, cor Vermelho Lovibond, $\beta$-caroteno e ácidos graxos livres, sugerindo o estudo da ativação da cinza para aumentar o potencial adsorvente. A temperatura de queima não apresentou uma influência coerente no potencial adsorvente. Kim (2008) estudou a estrutura da cinza da queima de casca de arroz para entender a adsorção de ácidos graxos livres do óleo de soja degomado, obtendo resultados satisfatórios para a cinza queimada obtida da queima de casca de arroz a $500{ }^{\circ} \mathrm{C}$. Hassanein et al. (2011) analisaram as cinzas de casca de amendoim como uma alternativa à terra clarificante no branqueamento do óleo bruto de soja, obtendo melhores resultados de branqueabilidade com concentração de $2 \%$ de cinzas queimadas à $500^{\circ} \mathrm{C}$ por 30 minutos. Entre misturas das cinzas com as terras clarificantes comerciais, uma mistura de 1:2 de cinza para a terra Tonsil-N forneceu a melhor branqueabilidade. Agatemor (2008) estudou o branqueamento do óleo de palma através do uso de cinzas de casca de banana. Os resultados indicaram que as cinzas reduziram significativamente os índices de cor, ferro, cobre, chumbo, fósforo e peróxidos, não sendo significativos os resultados para acidez.

Neste sentido, estudar a utilização das cinzas da queima de biomassa em caldeira como material adsorvente para remoção de substâncias indesejáveis do óleo de soja torna-se de grande importância industrial, visto que a substituição do adsorvente comercial pelas cinzas, mesmo parcial, reduz o montante do resíduo a sofrer destinação e também reduz o custo de refino do óleo. O objetivo deste trabalho é estudar a substituição parcial do adsorvente comercial utilizado no branqueamento do óleo de soja por cinzas provenientes da queima de cavaco de madeira em caldeira.

\section{MATERIAIS E MÉTODOS}

Para os experimentos foram utilizados óleo de soja neutro seco, óleo de soja branqueado, terra ativada comercial (TA) e cinzas de cavaco de madeira (CCM) fornecidos pela Cocamar, uma Cooperativa Agroindustrial da região norte do Paraná. 


\section{9 a 22 de outubro de 2014 \\ Florianópolis/SC}

Tanto o óleo de soja neutro-seco quanto o óleo branqueado foram caracterizados com relação ao teor de ácidos graxos livres, teor de clorofila, cor vermelho, sabões, densidade relativa e umidade. Os cinco primeiros índices foram determinados através de metodologias baseadas nos métodos oficiais da AOCS (Ca-5a-40, Cc-13d-55, Cc-13b-45, Cc-17-95, Cc-10a-25, respectivamente), e o último, através do método da estufa AOAC 1998.

$\mathrm{O}$ óleo neutro-seco foi submetido à etapa de branqueamento em planta industrial $\left(110^{\circ} \mathrm{C}, 40\right.$ min, 80 mbar de vácuo, média de $5 \mathrm{~kg}$ de adsorvente por tonelada de óleo processada), a fim de caracterizar o óleo branqueado e conhecer os teores das substâncias estudadas quando o óleo é branqueado industrialmente. O óleo branqueado foi caracterizado conforme os métodos já citados.

Os dois adsorventes utilizados nos experimentos, terra ativada e cinzas de cavaco de madeira, foram caracterizados quanto à umidade (método estufa AOAC1988), análise granulométrica (Método de Peneiramento para a CCM e Método de Microscopia para a TA), área específica BET, volume e diâmetro dos poros (Método BET por Adsorção de Nitrogênio a 77,4K), pH (Norma ASTM D3838 de 2011), morfologia (Microscopia Eletrônica de Varredura, MEV), caracterização microestrutural (Difratometria de Raios-X, DRX) e grupos funcionais específicos (Espectroscopia de Infravermelho com Transformada de Fourier, FTIR).

Os ensaios de cinética de adsorção foram conduzidos, tanto para adsorção com a TA quanto com a CCM, em duplicatas. Foram adicionados $2 \%$ em massa do adsorvente à massa de óleo neutroseco em erlenmeyer de $125 \mathrm{~mL}$. Este foi colocado em chapa de aquecimento à temperatura de $110^{\circ} \mathrm{C}$ por tempos de 5, 10, 15, 20, 30, 40, 60, 90, 120 e 180 minutos. Após cada tempo de adsorção, a mistura foi retirada da chapa e passou por processo de filtração simples. Cada amostra de óleo branqueado foi então caracterizada para possibilitar a determinação do tempo de equilíbrio da adsorção. Os dados obtidos a partir dos experimentos de cinética de adsorção foram ajustados aos modelos cinéticos de Pseudo-Primeira Ordem e Pseudo-Segunda Ordem de Lagergren.

Os ensaios de isotermas de adsorção foram conduzidos, tanto para adsorção com TA quanto com a CCM, em duplicatas. $\mathrm{O}$ adsorvente foi adicionado em diversas concentrações $(0,25 ; 0,5 ; 1,0$; 1,$5 ; 2,0 ; 3,0 ; 4,0$ e 5,0\% em massa) ao óleo neutro-seco em erlenmeyer de $125 \mathrm{~mL}$. Este foi colocado em chapa de aquecimento à temperatura de $110^{\circ} \mathrm{C}$, até que o tempo de equilíbrio determinado fosse atingido. A mistura foi então retirada da chapa e passou por processo de filtração. Cada amostra de óleo branqueado foi então caracterizada para possibilitar a análise das curvas de adsorção dos dois tipos de adsorventes testados. Os dados obtidos a partir dos experimentos de isotermas de adsorção foram ajustados aos modelos de isotermas de Langmuir, Freundlich, Redlich-Peterson e Sips.

\section{RESULTADOS E DISCUSSÕES}

O óleo neutro-seco (NS) foi inicialmente caracterizado com relação aos parâmetros de teor de ácidos graxos livres (acidez), sabões, clorofila, cor vermelho, densidade relativa e umidade. Este mesmo óleo foi submetido ao branqueamento industrial a fim de conhecer os teores do óleo após branqueamento em planta industrial. Os resultados encontram-se na Tabela 1, na qual são demonstrados também os valores determinados pela IN no 49 do MAPA/ANVISA (2006) para óleo 
refinado, a fim apenas de verificação da proximidade ao parâmetro de liberação do óleo refinado.

Tabela 1 - Resultados da caracterização do óleo neutro-seco

\begin{tabular}{cccc}
\hline Característica & $\begin{array}{c}\text { Resultado Óleo } \\
\text { NS }\end{array}$ & $\begin{array}{c}\text { Resultado Óleo } \\
\text { Branqueado } \\
\text { Industrialmente }\end{array}$ & Legislação* \\
\hline Acidez & $0,092 \%$ & $0,0735 \%$ & Máx. 0,1\% \\
Sabões & $31,2 \mathrm{ppm}$ & $3,69 \mathrm{ppm}$ & Máx. $10 \mathrm{ppm}$ \\
Clorofila & $1807 \mathrm{ppm}$ & $111 \mathrm{ppm}$ & - \\
Cor Vermelho & 3,2 & 1,6 & - \\
Densidade & $0,919 \mathrm{~g} / \mathrm{mL}$ & $0,919 \mathrm{~g} / \mathrm{mL}$ & $0,919 \mathrm{a} 0,925 \mathrm{~g} / \mathrm{mL}$ \\
Umidade & $0,082 \%$ & $0,079 \%$ & Máx. $0,1 \% \mathrm{~m} / \mathrm{m}$ \\
\hline & *Fonte: IN n n $^{\circ} 49$ MAPA/ANVISA (2006) para óleo refinado
\end{tabular}

Após a caracterização do óleo neutro-seco e do óleo branqueado industrialmente, os adsorventes foram caracterizados individualmente com relação à granulometria, área superficial específica, volume de poros, diâmetro de poros e pH. Os resultados são apresentados na Tabela 2. É possível observar que a terra ativada tem granulometria muito menor que a cinza e área específica aproximadamente 2 vezes maior. Já com relação ao volume e diâmetro de poros, são praticamente iguais para os dois adsorventes. Quando olhamos o resultado do $\mathrm{pH}$, vemos que a terra apresenta resultado bastante ácido, uma vez que ela é ativada quimicamente via ácido, enquanto que a cinza in natura ser rica em óxidos metálicos, os quais são normalmente básicos.

Tabela 2 - Caracterização da terra ativada (TA) e da cinza de cavaco de madeira (CCM)

\begin{tabular}{ccc}
\hline Característica & TA & CCM \\
\hline Diâmetro de partícula $(\mu \mathrm{m})$ & 15,99 & 98,61 \\
Área superficial $\left(\mathrm{m}^{2} / \mathrm{g}\right)$ & 135,0 & 69,28 \\
Volume de poros $\left(\mathrm{m}^{3} / \mathrm{g}\right)$ & $1,406 \mathrm{E}-2$ & $1,304 \mathrm{E}-2$ \\
Diâmetro de poros $(\AA)$ & 8,90 & 8,20 \\
$\mathrm{pH}$ & 2,30 & 13,31 \\
\hline *Fonte: IN $\mathrm{n}^{\circ}$ 49 MAPA/ANVISA (2006) para óleo refinado
\end{tabular}

Com relação à morfologia, foram analisados os dois adsorventes através de microscopia eletrônica de varredura (MEV) com aumento de 8.000 vezes. Os resultados podem ser visualizados na Figura 1 (A e D). Analisando a MEV da terra ativada (Figura 1A), é possível observar uma incidência grande de poros e fendas, bem como uma superfície um pouco mais homogênea. Já analisando o resultado para a CCM (Figura 1D), vemos que a incidência de fendas é grande, mas a incidência de poros é bastante inferior ao resultado com a TA. A superfície é mais heterogênea que a da TA.

A caracterização microestrutural dos dois adsorventes foi realizada através de análises de Difratometria de Raios-X (DRX). Os resultados encontrados estão apresentados na Figura 1 (B e E). 
Analisando os resultados da DRX da terra ativada (Figura 1B), verifica-se que há uma maior presença de montmorilonita (argilomineral base da terra ativada) e de quartzo (sílica), enquanto que para a CCM (Figura 1E) as maiores presenças são o quartzo e silicato de cálcio.

As análises de Espectroscopia de Infravermelho (FTIR) foram realizadas para os dois adsorventes, conforme é possível observar na Figura 1 ( $\mathrm{C}$ e F). Na terra ativada (Figura 1C) observase presença de grupamentos referentes à sílica e óxidos de alumínio, enquanto que na cinza de cavaco de madeira (Figura 1F) os grupamentos que se destacam são os referentes aos materiais carbonatados e os óxidos de sílica.

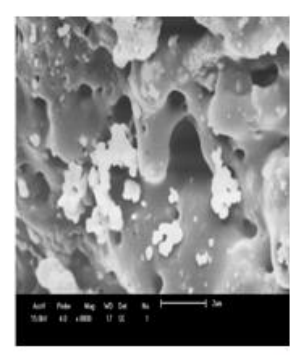

(A)

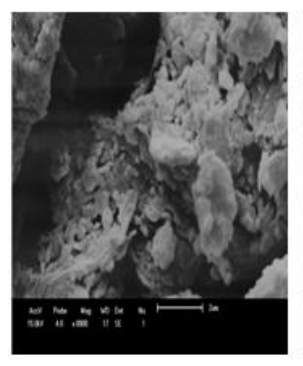

(D)
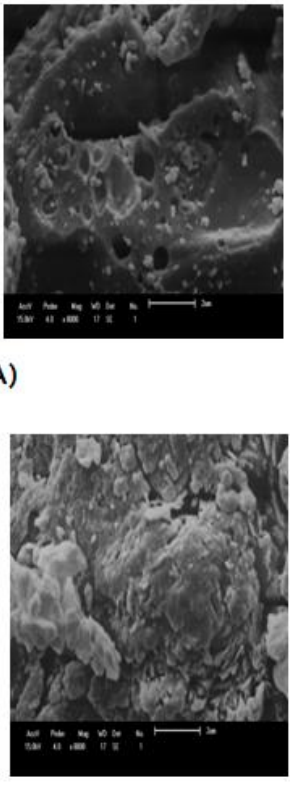

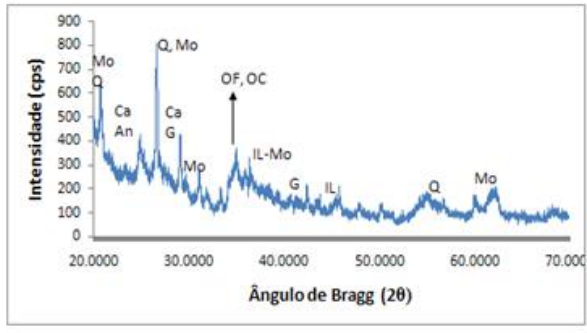

(B)

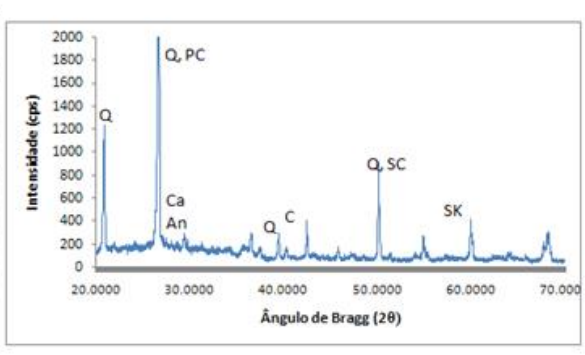

$(\mathrm{E})$

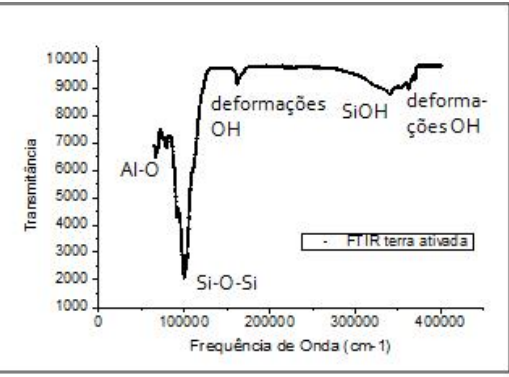

(C)

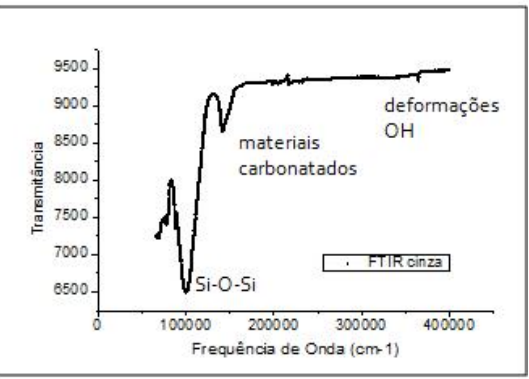

(F)

Figura 1 - Análises dos adsorventes. (A) MEV da terra ativada. (B) DRX da terra ativada. (C) FTIR da terra ativada. (D) MEV da cinza de cavaco. (E) DRX da cinza de cavaco. (F) FTIR da cinza de cavaco, onde em (B) e (E) Mo = montmorilonita, $\mathrm{Q}=$ quartzo, $\mathrm{Ca}=$ calcita, $\mathrm{An}=$ anidrita, $\mathrm{G}=$ gipsita, $\mathrm{OF}=$ óxido de ferro, $\mathrm{OC}=$ óxido de cálcio, $\mathrm{IL}=$ ilita, $\mathrm{PC}=$ fosfato de cálcio, $\mathrm{SC}=$ silicato de cálcio, $\mathrm{SK}=$ silicato de potássio

Para os experimentos da cinética de adsorção dos adsorbatos clorofila, cor vermelho e sabões do óleo em terra ativada, não foi possível ajustar os dados experimentais aos modelos cinéticos, uma vez que na primeira amostra do experimento ( 5 minutos) o equilíbrio já foi atingido (tempo de equilíbrio de 5 minutos para a TA). Para os ácidos graxos livres não foi possível obter o ajuste aos modelos cinéticos devido a ter ocorrido um aumento da acidez do óleo ao longo do experimento, fato explicado pela umidade do adsorvente ter proporcionado a formação de mais ácidos graxos livres.

Para a cinética de adsorção em CCM, também para acidez não foi possível obter ajuste aos 
modelos cinéticos. Já para os outros três adsorbatos os dados foram ajustados aos modelos de Lagergren, e os resultados estão apresentados na Tabela 3.

Tabela 3 - Ajustes dos dados experimentais aos modelos cinéticos de Lagergren

\begin{tabular}{ccc}
\hline Adsorbatos & $\begin{array}{c}\text { Melhor modelo } \\
\text { ajustado }\end{array}$ & $\mathrm{R}^{2}$ \\
\hline Ácidos Graxos Livres & - & - \\
Clorofila & Pseudo 1 $1^{\text {a Ordem }}$ & $96,35 \%$ \\
Cor Vermelho & Pseudo 1 1 Ordem & $90,19 \%$ \\
Sabões & Pseudo 1 1 Ordem & $89,27 \%$ \\
\hline
\end{tabular}

A partir dos dados obtidos no experimento de cinética de adsorção, foi determinado o tempo de equilíbrio para a adsorção em cinzas de cavaco de madeira em 90 minutos.

Com o tempo de equilíbrio determinado, os experimentos de isotermas de adsorção foram realizados. Tanto para TA quanto para CCM, não foi possível realizar ajuste dos dados experimentais de isotermas de adsorção para os ácidos graxos livres. Para os outros três adosrbatos, a Tabela 4 mostra os resultados dos modelos de isotermas que foram melhor ajustados aos dados experimentais dentre os estudados (Langmuir, Freundlich, Redlich-Peterson e Sips). Também na Tabela 4 estão apresentados os tipos de isotermas obtidos para cada adsorbato nos dois adsorventes, determinados através da análise gráfica das isotermas, em seguida contempladas na Figura 2.

Tabela 4 - Ajustes dos dados experimentais aos modelos de isotermas para TA e CCM

\begin{tabular}{ccccccc}
\hline Adsorbato & $\begin{array}{c}\text { Melhor } \\
\text { modelo } \\
\text { ajustado }\end{array}$ & $\mathrm{R}^{2}$ & $\begin{array}{c}\text { Tipo da } \\
\text { Isoterma }\end{array}$ & $\begin{array}{c}\text { Melhor } \\
\text { modelo } \\
\text { ajustado }\end{array}$ & $\mathrm{R}^{2}$ & $\begin{array}{c}\text { Tipo da } \\
\text { Isoterma }\end{array}$ \\
\hline \multicolumn{3}{c}{ Terra Ativada } & \multicolumn{3}{c}{ Cinza de Cavaco de Madeira } \\
\hline $\begin{array}{c}\text { Ácidos } \\
\text { Graxos } \\
\text { Livres }\end{array}$ & - & - & - & - & - & - \\
$\begin{array}{c}\text { Clorofila } \\
\text { Cor }\end{array}$ & Sips & $96,774 \%$ & Favorável & Sips & $78,856 \%$ & Desfavorável \\
Vermelho & Freundlich & $92,060 \%$ & Favorável & Sips & $93,022 \%$ & Linear \\
Sabões & Langmuir & $87,492 \%$ & Linear & Sips & $78,889 \%$ & Desfavorável \\
\hline
\end{tabular}

Através dos resultados das isotermas, é possível notar que, para a TA, a adsorção de clorofila segue o modelo de Sips e, pela análise dos parâmetros do modelo, a adsorção acontece em superfície homogênea e seguindo mais o modelo de Langmuir do que o de Freundlich. A adsorção de cor vermelho segue o modelo de Freundlich, sendo que ocorre em superfície mais heterogênea, reversível e policamada, sugerindo fisissorção. A adsorção de sabões em TA segue o modelo de Langmuir, sugerindo adsorção em superfície homogênea e monocamada e regida pela quimissorção. 
Já para as isotermas com CCM, observa-se que os três adsorbatos seguem o modelo de adsorção de Sips. Analisando os parâmetros do modelo obtidos identifica-se que os três adsorbatos seguem mais o modelo de Langmuir do que o de Freundlich.

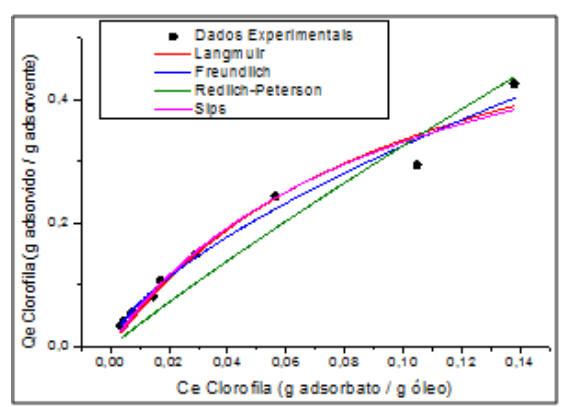

(A)

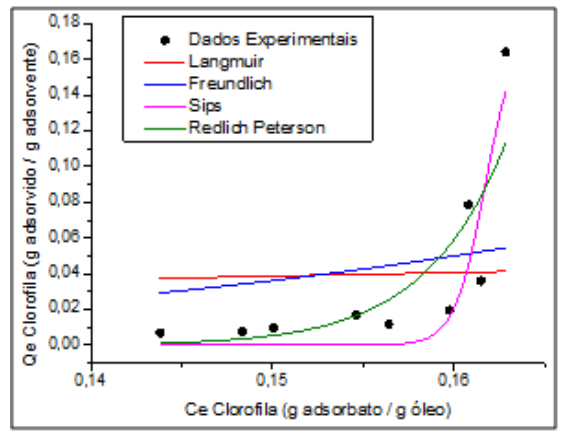

(D)

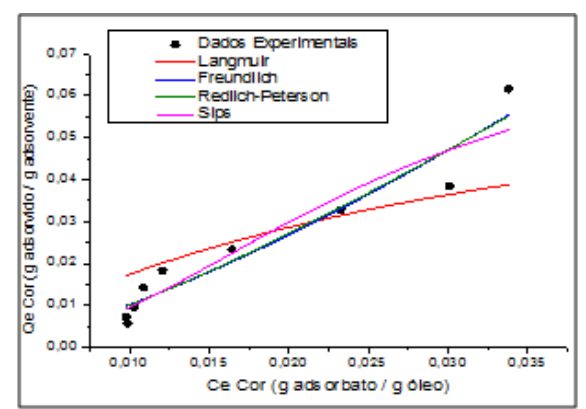

(B)

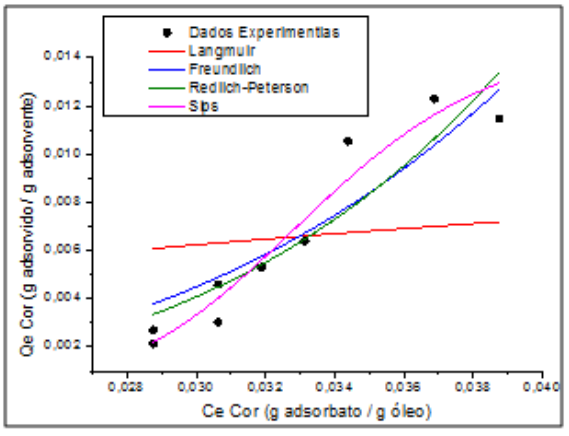

(E)

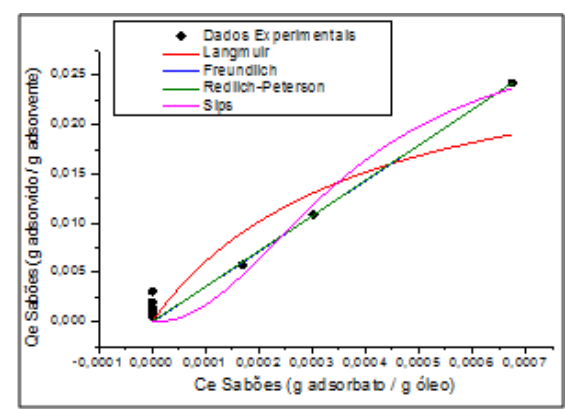

(c)

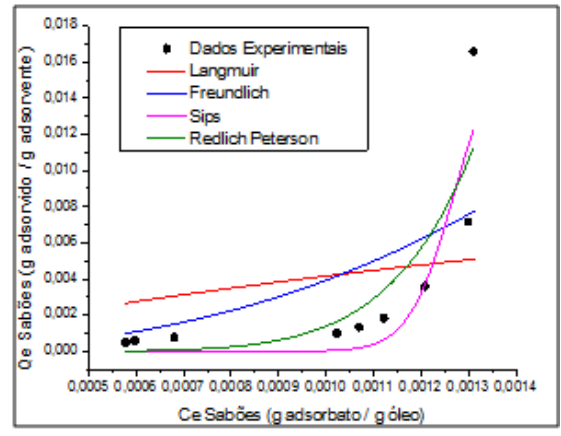

(F)

Figura 2 - Ajustes dos dados experimentais aos modelos de isotermas. (A) Clorofila em TA. (B) Cor vermelho em TA. (C) Sabões em TA. (D) Clorofila em CCM. (E) Cor vermelho em CCM. (F) Sabões em CCM.

Comparando a quantidade de adsorbato adsorvido do óleo, nos tempos de equilíbrio (90 minutos para TA e 5 minutos para CCM) e com concentração de adsorvente de $2 \% \mathrm{~m} / \mathrm{m}$, obtemos os resultados apresentados na Tabela 5.

Tabela 5 - Potencial de remoção dos adsorbatos em TA e CCM

\begin{tabular}{ccc}
\hline Adsorbato & Potencial de remoção - TA & Potencial de remoção - CCM \\
\hline Ácidos Graxos Livres & - & - \\
Clorofila & $90 \%$ & $18 \%$ \\
Cor Vermelho & $76 \%$ & $28 \%$ \\
Sabões & $100 \%$ & $69 \%$ \\
\hline
\end{tabular}

\section{CONCLUSÕES}




\section{9 a 22 de outubro de 2014 \\ Florianópolis/SC}

Os resultados obtidos no trabalho demonstraram que a terra ativada mostrou potencial de remoção alto para cor vermelho (76\%), clorofila (90\%) e sabões (100\%), e para ácidos graxos livres não se mostrou efetiva. Com o adsorvente proposto, a cinza, os resultados do potencial de remoção foram menores do que os apresentados pela terra (28\%, $18 \%$ e $69 \%$ respectivamente), e a cinza também não se mostrou efetiva para remoção de ácidos graxos livres.

A diferença entre os potenciais de remoção dos adsorbatos estudados utilizando como adsorvente a terra ativada (TA) e a cinza de cavaco de madeira (CCM) sugere que a substituição total do adsorvente comercial pela cinza não é tecnicamente viável, visto que o adsorvente de baixo custo proposto neste trabalho não forneceu óleo branqueado com as características necessárias para as etapas subseqüentes ao branqueamento no refino do óleo.

Quando analisamos isoladamente os resultados do potencial de remoção de cor vermelho, clorofila e sabões do óleo com CCM, fica evidente a possibilidade da substituição parcial (blends de terra ativada e cinza) ou da realização de pré-tratamento do óleo neutro-seco com a CCM antes da etapa de branqueamento com TA. Estas alternativas tornam possível a redução do consumo específico do adsorvente comercial

\section{REFERÊNCIAS}

AGATEMOR, C. Some aspects of palm oil bleaching with activated plantain peel ash. Food Science Technology Resource, v. 14, n. 3, p. 301-305. 2008.

ANEEL. Atlas de Biomassa, 2008. Disponível em <http://www.aneel.gov.br/arquivos/pdf/atlas_par2_cap4.pdf〉. Acessado em 26 de maio de 2013.

BRASIL. Ministério da Agricultura, Pecuária e Abastecimento. Instrução Normativa n.49, de 22 de dezembro de 2006. Dispõe sobre o regulamento técnico de identidade e qualidade dos óleos $\begin{array}{lllll}\text { vegetais } & \text { refinados. } & 2006 . & \text { Disponível em }\end{array}$ 〈http://www.codapar.pr.gov.br/arquivos/File/pdf/oleos_veg_ref_in_49_06.pdf〉. Acessado em 20 de junho de 2013.

CHIRENJE, T.; MA, L.Q.; LU, L. Retention of $\mathrm{Cd}, \mathrm{Cu}, \mathrm{Pb}$ and $\mathrm{Zn}$ by wood ash, lime and fume dust. Water, Air and Soil Pollution. v. 171, p. 301-314, 2006.

HASSANEIN, M.M.M.; EL-SHAMI, S.M.; TAHA, F.S. Evaluation of peanut hulls as an alternative to bleaching clays.Grasas y Aceites, v. 62, n. 03, p. 299-307. 2011.

KIM, M.; YOON, S.H.; CHOI, E.; GIL, B. Comparison of the adsorbent performance between rice hull ash and rice hull silica gel according to their structural differences. LWT, v. 41, p. 701-706. 2008.

LIN, T.; LIN, C. Performances of peanut hull ashes in bleaching water-degummed and alkalirefined soy oil.Journal of the Taiwan Institute of Chemical Engineers, v. 40, p. 168-173. 2009. 